Article

\title{
Scenarios of Nutrient-Related Solute Loading and Transport Fate from Different Land Catchments and Coasts into the Baltic Sea
}

\author{
Yuanying Chen ${ }^{1,2, *}$, Vladimir Cvetkovic ${ }^{1}$ and Georgia Destouni ${ }^{2}$ (D) \\ 1 Department of Sustainable Development, Environmental Science and Engineering, Royal Institute of \\ Technology (KTH), 10044 Stockholm, Sweden \\ 2 Department of Physical Geography, Stockholm University, 10691 Stockholm, Sweden \\ * Correspondence: yuanying@kth.se or yuanying.chen@natgeo.su.se; Tel.: +46-8-790-7382
}

Received: 23 May 2019; Accepted: 3 July 2019; Published: 9 July 2019

\begin{abstract}
This study uses controlled numerical experimentation to comparatively simulate and investigate solute transport and concentration responses and patterns in the Baltic Sea for various solute releases from the land through two different coastal cases. These cases are the Swedish Kalmar County coast and the Polish coast of the Vistula River outlet. For equivalent solute releases, the coastal flow conditions and their interactions with main marine currents determine the local coastal solute spreading, while the overall spreading over the Baltic Sea is similar for the two coastal cases, despite their large local differences. For nutrient-proportional solute release scenarios, the highly-populated Vistula catchment yields much greater total, but smaller per-capita nutrient impacts, in the Baltic Sea than the Kalmar County catchment. To be as low as from the Vistula catchment, the per-capita nutrient contribution from Kalmar County would have to be reduced much more than required on average per Swedish inhabitant by the Baltic Sea Action Plan. This highlights an unfairness issue in the per-capita distribution of nutrient load allowance among the Baltic countries, which needs to be considered and handled in further research and international efforts aimed to combat the Baltic Sea eutrophication.
\end{abstract}

Keywords: solute transport; Baltic Sea; nutrient loads; coastal concentrations; marine concentrations; Baltic Sea Action Plan; FVCOM simulations

\section{Introduction}

The Baltic Sea is an important semi-enclosed sea environment in northern Europe. Surrounded by several countries that span a total drainage basin of around 1,739,400 $\mathrm{km}^{2}$ [1], the Baltic Sea receives large nutrient loads from land and suffers severe eutrophication problems [2]. Nutrient pathways through coastal zones to the Baltic Sea have been investigated in previous research [3,4], and numerical models have been developed and applied to improve our understanding of transport dynamics, e.g., in terms of water exchange times and particle-tracked transport pathways [5-10]. Most transport studies, however, have focused on the local scale of a certain part or marine basin of the Baltic Sea [5-9], with few studies considering the full-scale range of transport from land loading into and through local estuaries and coasts to the whole Baltic Sea $[10,11]$. Such studies are needed for advancing our ability to accurately assess the contributions of different countries to the eutrophication (and pollution) of the Baltic Sea [12].

This paper contributes to such advancement by using an adapted, tested and validated hydrodynamic model [13] for controlled numerical experimentation aimed at advancing our understanding of physical solute transport through different coastal conditions and further into the Baltic Sea. The numerical 
experimentation includes a comparison of different water discharge conditions combined with various solute load scenarios from land, and simulation of the further solute transport, fate and concentration impacts in the Baltic Sea through two hydro-climatically, hydrodynamically and geomorphologically different Baltic coast cases. The two cases are (Figure 1): (1) The Kalmar County coast in south-eastern Sweden, with relatively small and diffuse freshwater discharges to the sea distributed along the whole coastline [14,15] feeding into a mainly southwards coastal water flow through the Kalmar Strait (red arrow by coast 1 in Figure 1a), and further into a main marine water current that is also mainly southwards, parallel to this coastline (blue arrow by coast 1 Figure 1a); and (2) the coast of the Vistula River outlet in northern Poland, with large river discharge to the coast feeding into a circulating coastal water flow through and out from the Gulf of Gdansk (red arrow by coast 2 in Figure 1a), and further into a northwards main marine water current (blue arrow by coast 2 in Figure 1a). These two cases also represent different hydro-climatic land conditions. In the Swedish water management district of Southern Baltic Proper that includes Kalmar County, average annual precipitation and runoff (discharge divided by catchment area) are around $744 \mathrm{~mm} /$ year and $242 \mathrm{~mm} / \mathrm{year}$, respectively [16]. Even though its river discharge is large $\left(1027 \mathrm{~m}^{3} / \mathrm{s}\right)$, because the runoff-integrating catchment area is large $\left(194,000 \mathrm{~km}^{2}\right)$, the Vistula River catchment is on average drier, with annual average precipitation varying spatially within the range 550-650 mm/year over most of the catchment and annual average runoff being around $167 \mathrm{~mm} / \mathrm{year}$ [17].

(a)

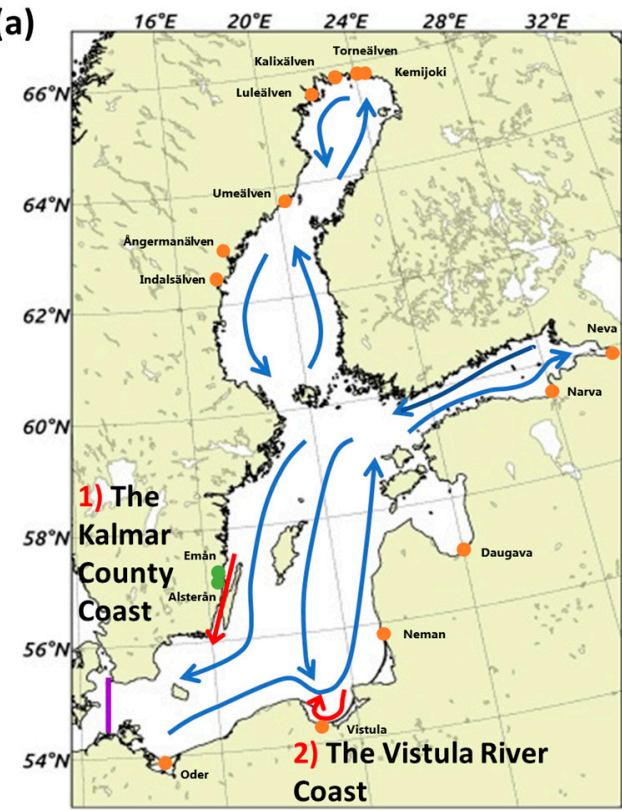

(b)

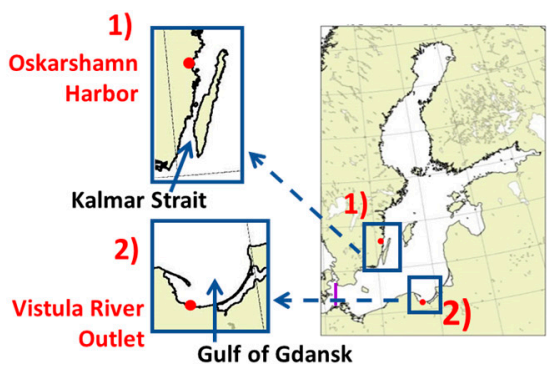

(c)

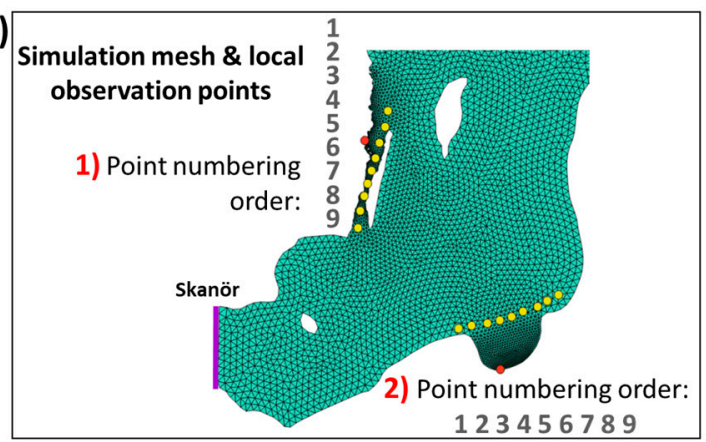

Figure 1. (a) The Baltic Sea locations of the (1) Kalmar County and (2) Vistula River coastal cases are shown with the associated main coastal (red arrows) and marine (blue arrows) water flows; orange dots show the locations of the 13 largest river outlets along the whole Baltic coast and green dots show the outlet locations of two relatively small local rivers at the Kalmar coast. (b) Focused illustration of the two simulated coastlines and respective solute source release locations (red dots). (c) Simulation mesh and local observation points for solute transport results along each coastline (yellow dots, numbered in shown order).

The main Baltic Sea flow and circulation pattern (blue arrows, Figure 1a) is determined by the prevailing coastline, bathymetry, wind and boundary inflow conditions, with our simulation study yielding consistent results for this pattern as several previous studies [13,18-20]. With these validated hydrodynamic patterns determining physical solute transport, the numerical experimentation in this paper investigates how the local coastal flows carry and physically transport solute into the closest main marine current and further into the whole sea, which is an essential basic question for water quality and ecosystem conditions. The freshwater discharges and coastal flows are expected to be most important 
for near shore solute concentrations, while the marine current is expected to be dominant for the further concentration distribution in the sea. A core issue is then how far from the coastline the coastal flow controls the physical solute transport under different coastal hydro-climatic, geomorphological and hydrodynamic conditions and various solute release scenarios.

To resolve this issue through controlled numerical experimentation, we simulate the transport and concentration patterns, and main similarities and differences in these, for various scenarios of generic solute releases from land into the two coastal cases and further into the Baltic Sea. The solute releases are applied at the point source example of Oskarshamn Harbor in the Kalmar case and the Vistula River outlet in the Vistula case (red dots in Figure 1b). The solute release scenarios are also compared with reported loads of total nitrogen (TN) and total phosphorus (TP) from the two coastal catchments, in total and per-capita terms. These comparisons enable reflection on some social issues of nutrient management and mitigation efforts, as they also consider catchment population influences and implications, which previous studies have reported as strongly correlated with nutrient contributions to the Baltic Sea [21,22] and important for fairness issues in the regional nutrient mitigation efforts [12].

\section{Materials and Methods}

\subsection{The Baltic Sea and Two Coastal Study Cases}

The Baltic Sea is a brackish semi-enclosed sea system in northern Europe, with the narrow Danish straits being its connections to Kattegat and further to the North Sea (west of the purple boundary line delimiting the Baltic Sea simulation domain in Figure 1). The Baltic is located between $10^{\circ} \mathrm{E}$ and $30^{\circ} \mathrm{E}$ longitude, and $53^{\circ} \mathrm{N}$ and $66^{\circ} \mathrm{N}$ latitude (Figure 1a). It receives total freshwater discharges of around $15,200 \mathrm{~m}^{3} / \mathrm{s}$ [23], which also carry major loads of nutrients from the surrounding countries [22,23]. The general circulation pattern of the Baltic Sea is as indicated in Figure 1a (blue arrows) [13,18-20]; with relatively persistent main marine currents [20].

The Kalmar County coastline in south-eastern Sweden (part of the western Baltic Sea coast) and the island of Öland a bit further to the east frame the narrow Kalmar Strait (Figure 1b). Along the Kalmar County coastline, the Oskarshamn Harbor is selected as an example of a main point source input location (Figure 1b), to represent typical conditions and simulate various scenarios of solute release and coastal-marine transport in this type of coast with mainly small and diffuse freshwater discharges to the sea distributed along the coastline.

In the second coastal study case, the large Vistula River discharges into the Gulf of Gdansk (Figure 1b), which opens into the Baltic Proper marine basin. The Vistula River is the second largest river flowing into the Baltic Sea [23] and its freshwater discharge to the sea carries with it the highest river-borne Baltic TN and TP loads, representing 9\% and 14\% of total loads in 2014, respectively [24]. As such, simulation of solute release and further coastal-marine transport in this coastal case study represents a Baltic coast type with large river discharge and associated large channelized solute (nutrient, pollutant) loading into the Baltic Sea.

\subsection{Problem Formulation and Simulation Scenarios}

For each of the two coastal case studies, we consider three different release scenarios. In the first, basic scenario (referred to as the equivalent release scenario), the solute mass released from each coastal catchment is the same for the two cases; through this scenario, we can study the coastal-marine spreading patterns and concentration levels that develop in the Baltic Sea from similar solute releases at different coastal locations with different flow conditions. In the second scenario (referred to as the total nutrient scenario), solute releases are proportional to total average annual loads of TN and TP from the catchments of the two coastlines; through this scenario, we can study the influence of different total catchment loads on concentration spreading patterns in the Baltic Sea. In the third scenario (referred to as the per-capita nutrient scenario), solute releases are proportional to average annual TN and TP loads per capita from the populations living in the catchments of the two coastlines. Through this 
scenario, we can also take into account and study a social fairness dimension regarding the Baltic nutrient contributions of the average catchment inhabitant in the two coastal cases.

\subsection{Simulation and Analysis Approach}

This study uses the three-dimensional ocean model FVCOM (Finite-Volume, primitive equation Community Ocean Model) [25] to simulate the hydrodynamic and solute transport processes in the Baltic Sea. FVCOM is based on primitive equations of momentum to simulate free-surface motion, and uses the Mellor and Yamada turbulence closure model [26] and Smagorinsky eddy parameterization method to account for vertical and horizontal turbulence mixing along with the finite volume method for discretization that leads to good mass conservation [25]. Furthermore, the discretization uses an unstructured triangular grid horizontally and sigma layers vertically for a good representation of complicated coastlines and bathymetry. FVCOM has been successfully applied to simulation studies of different free surface water bodies [27-29], and specifically adapted, tested and validated for applications, such as that of the present study, to the Baltic Sea [13].

In this study, FVCOM is used to simulate the Baltic coastal-marine hydrodynamics and associated inert solute transport over the five-year period of 2005-2009, based on the model adaptation and validation described by Chen et al. [13]. The FVCOM Baltic Sea model successfully reproduces general flow patterns consistently with other Baltic Sea studies [18-20] and water level results in accordance with observed data; this shows good model capability in capturing the hydrodynamic processes and conserving water mass. Moreover, model results are in good agreement with observed water salinity and temperature data at different depths and points in time, which shows good model capability in reproducing scalar mixing and transport processes in the sea.

In this study, the model is driven by the external forcings of (based on observation-based data available for the simulation period 2005-2009) [13]: Wind and heat flux over the Baltic Sea [30-32]; water level, water temperature and salinity at the open boundary of Skanör [33,34]; and the freshwater discharges to the sea from the 13 largest rivers in its total catchment (accounting for around $65 \%$ of the total river discharge into the present Baltic Sea simulation domain [35,36]; orange dots, Figure 1a) and the two main local river discharges at the Kalmar coast (green dots, Figure 1a; accounting for around $0.5 \%$ of the total discharges from the 13 largest rivers) in order to accurately simulate the local hydrodynamic and transport processes at this coast. External forcings are given at a daily temporal resolution. The triangular model mesh has a finer resolution of $2 \mathrm{~km}$ in the coastal zones of Kalmar Strait and Gulf of Gdansk, and extends gradually to a coarser resolution of $10 \mathrm{~km}$ for the whole Baltic Sea (Figure 1c). In the vertical, the depth is divided into 20 uniform sigma layers. The simulation domain boundary and connection to Kattegat and the North Sea is set at Skanör (purple boundary line, Figure 1c).

For the solute transport simulations, a constant (normalized, dimensionless) concentration of 1 is released over the whole depth at the source location of Oskarshamn Harbor in the Kalmar coast case. In the equivalent release scenario, a corresponding resulting solute load into the sea is also released (as a mass flux boundary condition) at the Vistula River outlet in that coastal case (red dots in Figure 1b). All the results for solute concentration shown in this paper regard depth-averaged concentration. To quantify and illustrate the local transport patterns, nine coastal observation points are also chosen for each case, as shown in Figure 1c (yellow dots). In addition to quantifying the solute transport and concentration patterns at these coastal points and further into the sea, we also carry out a spectral analysis of the results of this scenario for investigating dominant correlations between concentration fluctuations and fluctuations in other main flow and transport variables, such as wind and water flow velocity. Power spectral density (PSD) is used for these variables and solute concentration to identify possible similar periodicities and driver-effect chains in the data time series. Magnitude-squared coherence is also used to test the coherence between solute concentration and other variables in different periodicities. $95 \%$ significance level is calculated according to the formula widely discussed in previous research $[37,38]$. 
For the total nutrient scenario, we consider the following annual average nutrient loads to the sea. For the Kalmar case (1), we use 3341 tons/year for TN and 100 tons/year for TP as reported for the period 1984-2000 for loads originating from the mainland part of Kalmar County to the North and South Kalmar Strait [39,40]. For the Vistula case (2), we use 119,080 tons/year for TN and 5510 tons/year for TP as reported for the period 1980-1993 for the Vistula River loading to the sea [41]. To represent these total nutrient load proportions in this scenario, the simulated solute releases to the sea are 35.6 and 55.1 times greater in the Vistula than in the Kalmar case, based on the associated total TN and TP loads, respectively.

For the per-capita nutrient scenario, we consider the following average contributions per person to total annual average TN and TP loads. For the Kalmar case (1), we use $21.6 \mathrm{~kg} / \mathrm{year}$ of TN and $0.624 \mathrm{~kg} /$ year of TP for the reported total loads of $5244 \mathrm{tons} /$ year of TN and 151.8 tons/year of TP from the whole Kalmar County [39,40] with a total population of 243,219 [42]. For the Vistula case (2), we use $5.07 \mathrm{~kg} /$ year of TN and $0.235 \mathrm{~kg} /$ year of TP for the above-mentioned total nutrient loads $(119,080 \mathrm{tons} /$ year for TN and 5510 tons/year for TP) from the Vistula River catchment with a population of 23,487,300 [43]. To represent the average per-capita nutrient load proportions in this scenario, the simulated solute releases to the sea are 4.3 and 2.7 times smaller in the Vistula than in the Kalmar case, for the per-capita TN and TP loads, respectively. Note that in the total nutrient scenario, we account for the nutrient loads released into the Kalmar Strait, which are from just two districts of the Kalmar County, while in the per-capita nutrient scenario, the considered population and nutrient loads represent the whole Kalmar county (four districts in total) for consistent estimation of average per-capita loads [39,40].

\section{Results and Discussion}

\subsection{Coastal Transport Characterization}

For an overall comparison of coastal solute transport and concentration patterns in the basic equivalent release scenario, Figures 2 and 3 show the resulting temporal average northwards component of flow velocity (Figures $2 a$ and $3 a$ ), and concentration (Figures $2 b$ and $3 b$ ) at the different coastal observation points (Figure 1c), and a statistical summary of concentration values at the points with the lowest and the highest values (Figures $2 \mathrm{c}$ and $3 c$, showing box-and-whisker plots of the concentration statistics at these points) for each coastal case (Kalmar in Figure 2, Vistula in Figure 3). The mainly negative values of the northwards velocity component in the Kalmar case shows the predominantly southwards coastal flow through the Kalmar Strait in that case, while the coastal flow directions vary (positive and negative values) in the Vistula case.

As a consequence of the predominant southwards coastal flow, the coastal solute transport is also predominantly southwards in the Kalmar case with overall higher concentrations south than north of the source location along that coastline. Solute concentration is also overall decreasing towards the south with increasing distance from the source location through the Kalmar Strait. In the more complex coastal flow field of the Gulf of Gdansk, in the Vistula case, average solute concentration in each simulation year is smallest at around the midpoint of the outer bay boundary (where the observation points are located, Figure 1c). This is because the strong marine current from the Southern Baltic Proper penetrates and brings in fresher water there than at the fringes of the bay (Figure 1a). Moreover, the distance from the source at the coastline is relatively long along the circulating main coastal flow direction to that midpoint.

Overall, the average and the maximum coastal solute concentrations are much (order-of-magnitude) higher in the Kalmar than in the Vistula case. This is because the large Vistula River discharge must have a much smaller solute concentration level than the smaller and more diffuse Kalmar coast discharges in order for both coasts to receive the same solute loading (product of discharge and concentration) in the equivalent release scenario. Minimum concentrations are of a similar order in both cases because concentration values are so small north of the solute source location in the Kalmar case, since only small amounts of solute are transported northwards in the Kalmar Strait. 
(a)

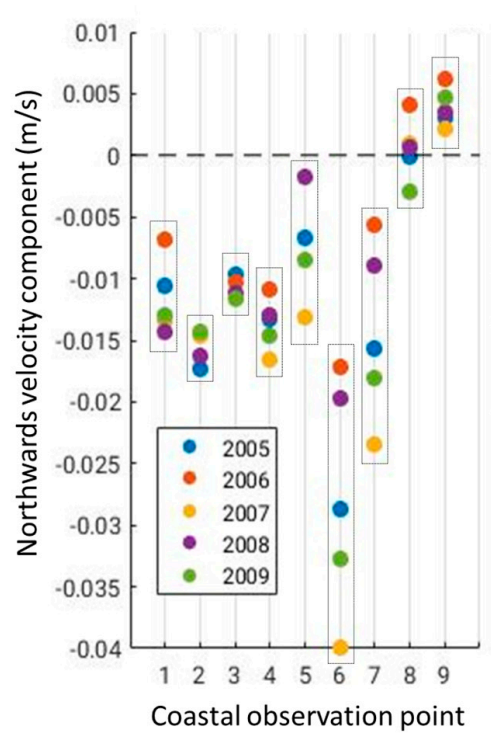

(b)

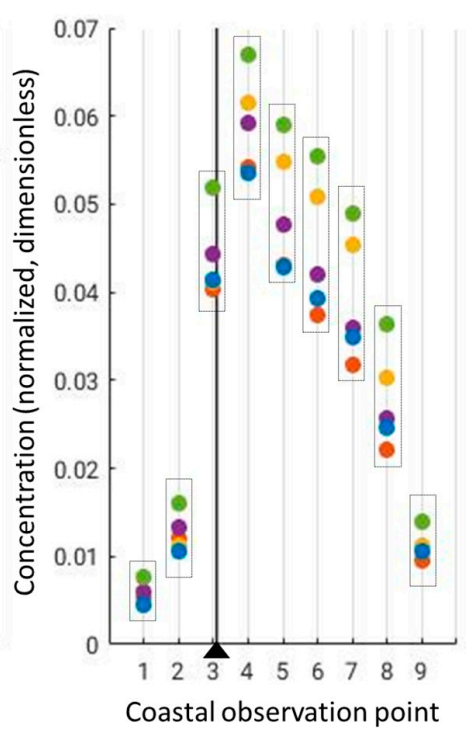

(c)

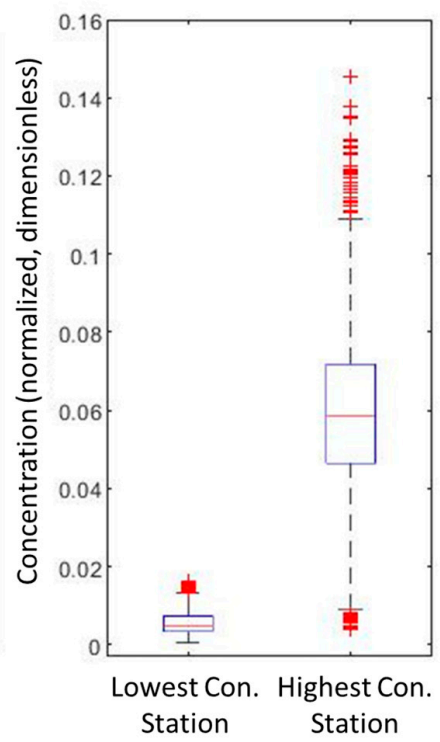

Figure 2. (a) Temporal average northwards velocity component $(\mathrm{m} / \mathrm{s})$. (b) Temporal average solute concentration (normalized, dimensionless). (c) Box-and-whisker plots of the statistics of concentration values (median, lower and upper quartiles, whiskers of 1.5 times the interquartile range, and individual outlier data outside of the whisker range) at the observation points with the lowest and the highest concentration. Results are for the Kalmar County coast and the symbol $\boldsymbol{\Delta}$ in panel (b) indicating the solute source location along this coastline.

(a)

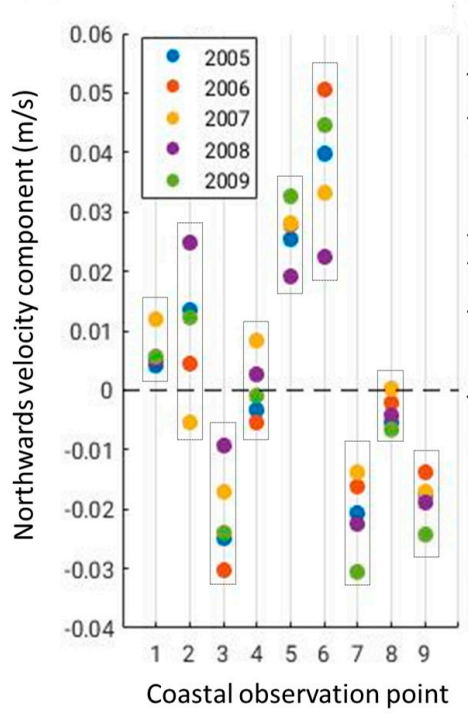

(b)

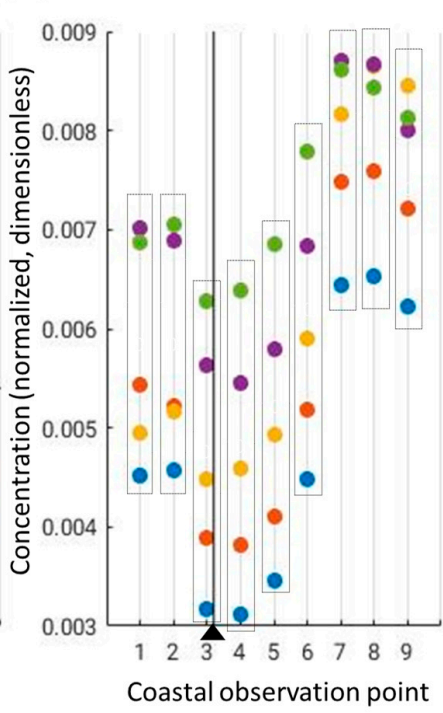

(c)

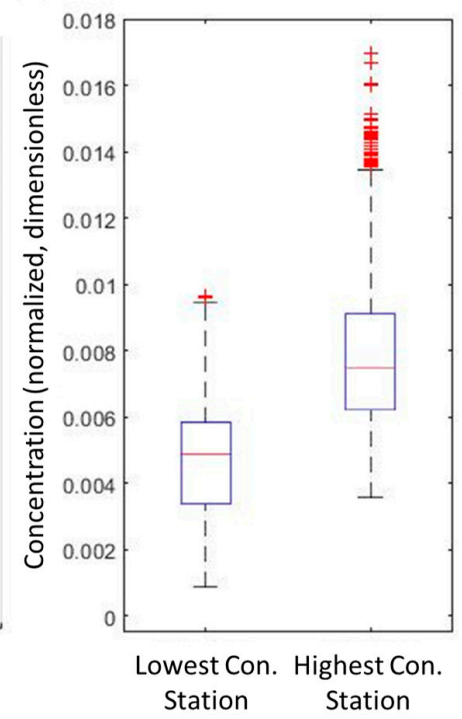

Figure 3. (a) Temporal average northwards velocity component $(\mathrm{m} / \mathrm{s})$. (b) Temporal average solute concentration (normalized, dimensionless). (c) Box-and-whisker plots of the statistics of concentration values (median, lower and upper quartiles, whiskers of 1.5 times the interquartile range, and individual outlier data outside of the whisker range) at the observation points with the lowest and the highest concentration. Results are for the Vistula River coast with the symbol $\boldsymbol{\Delta}$ in panel (b) indicating the solute source location along this coastline.

\subsection{Coastal Transport Correlations and Drivers}

For the basic equivalent release scenario, we here use PSD to analyze variables, such as water level, wind velocity (northwards and eastwards), water velocity (northwards and eastwards) and 
solute concentration. Water elevation is chosen at the open boundary at Skanör (purple lines, Figure 1). Northwards and eastwards wind velocities are calculated as an average of the nine observation points in each coastal case (Figure 1c) because it is the wind fields that drive the total motion of the water over the local coastal scale rather than wind at a single point. For the variables of northwards water velocity, eastwards water velocity and solute concentration, value at a point (Point No. 7 in both cases, Figure 1c) is selected as an example for case comparison. In Supplementary Material (SM), comparative results are also shown for average values in the Kalmar case, where the coastal water flow situation is relatively unidirectional southwards, whereas averaging over the more complex coastal flow field in the Vistula case dampens fluctuations and thereby obscures information. A more detailed description of PSD implementation using average or point values is given in Supplementary Material.

Variables with similar periodicities as solute concentration are identified and shown in Figures 4a and 5a. Variables that do not have similar periodicities as solute concentration are also shown for comparison in Figures $4 \mathrm{~b}$ and $5 \mathrm{~b}$. Magnitude-squared coherences of solute concentration with all the variables, and their significant level $[37,38]$ are shown in Figure 6.

(a)

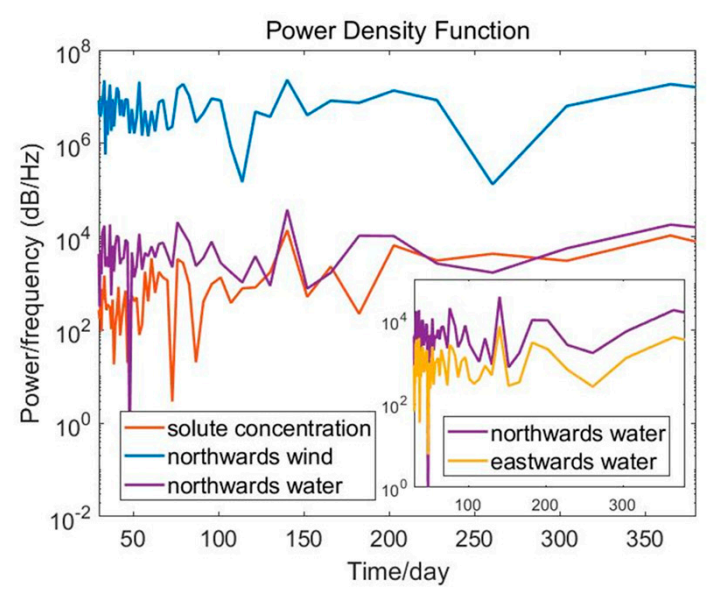

(b)

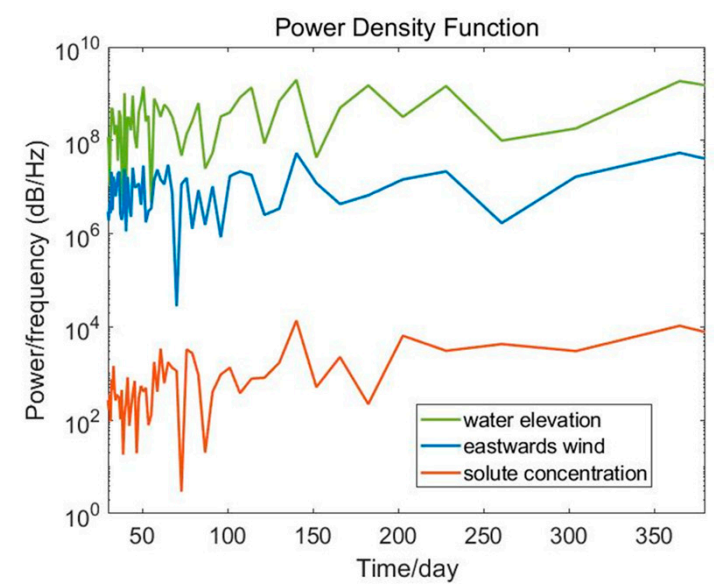

Figure 4. Power spectral density (PSD) analysis for the Kalmar County coast case. (a) PSDs of relatively strongly correlated variables; (b) PSDs of weakly correlated variables.

(a)

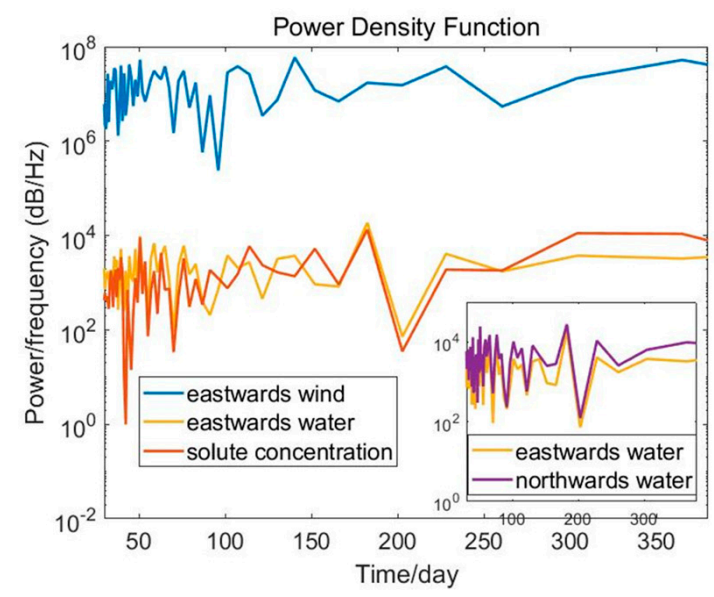

(b)

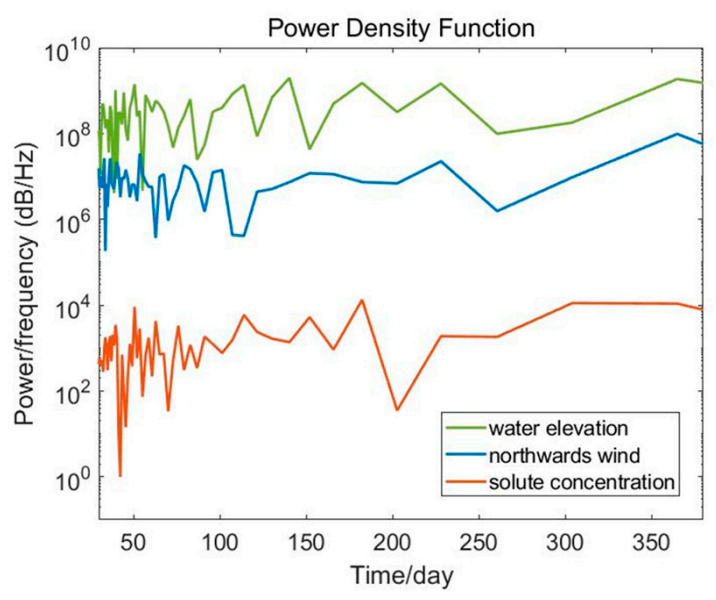

Figure 5. PSD analysis for the Vistula River coast case. (a) PSDs of relatively strongly correlated variables; (b) PSDs of weakly or not correlated variables. 
(a)

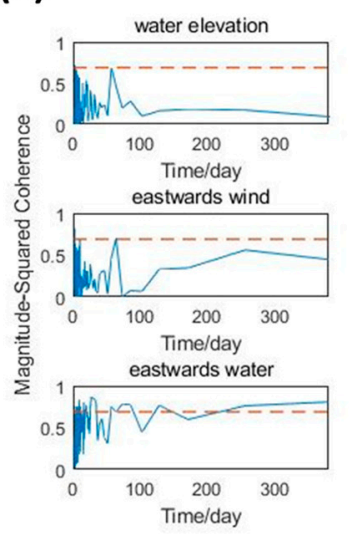

(b)

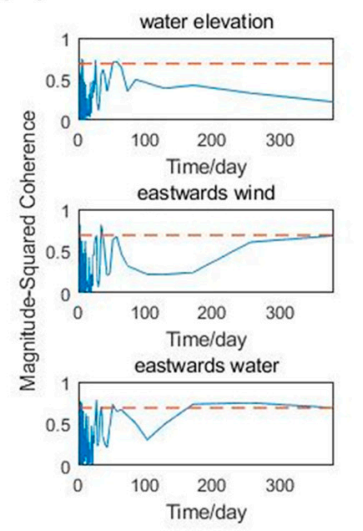

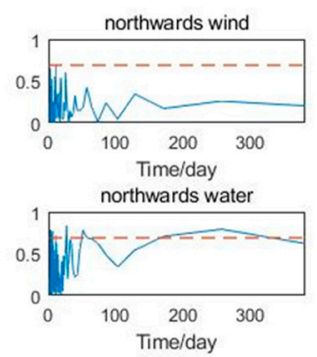

Figure 6. Magnitude-squared coherence of solute concentration with different forcing variables. (a) The Kalmar coast case. (b) The Vistula coast case. Red dashed line shows coherence at a 95\% significance level.

In the Kalmar case, (negative) northwards wind velocity, (negative) northwards and eastwards water velocity, and coastal solute concentration have similar periodicities (Figure 4a), indicating a chain of influence from wind driving coastal water flow that in turn drives solute distribution in this case. Figure 6a also shows this relationship with relatively high and significant coherence. Results for average variable values across all nine coastal observation points for northwards water velocity, eastwards water velocity and solute concentration are given in the Supplementary Material (Figures S1 and S2) and show similar patterns. In the Vistula case, the solute concentration periodicities are similar to those of eastwards and northwards flow and to some, lesser, degree with those of eastwards wind (Figure 5a). The magnitude-squared coherence also shows solute concentration as significantly correlated with eastwards and northwards water flow, and at some periodicities also with the eastwards wind (Figure 6b). These results reflect the hydrodynamic and transport conditions at the Vistula River case, where the flow is dominated by stable marine currents and the transport process is less influenced by the local wind conditions. Results for several other coastal observation points than the main comparative point 7 are shown in the Supplementary Material (Figures S3-S6) with further explanations (Supplementary Material text Section S1.2).

\subsection{Solute Concentration Spreading into the Baltic Sea}

In the basic equivalent release scenario, solute from the Kalmar County coast is first transported southwards by the coastal flow through the Kalmar Strait and thereafter continues to spread with the marine current from the southwest part and further northwards and over the whole Baltic Sea (Figure 7a). Analogously for the Vistula River coast, solute first spreads through the Gulf of Gdansk by the circulating coastal flow, then follows the marine current through the eastern part and further northwards and over the Baltic Sea (Figure 7b). The coastal source locations and flow conditions lead to different spreading pathway details in the two cases. Overall, however, the main coastal-marine spreading patterns are similar between the cases in an equivalent release scenario. That is, more or less similarly high concentrations occur around the coastal sources and decrease with distance from the coast into the Baltic Sea, despite the large differences in local flow situations, including freshwater discharges and coastal and marine flows. 
(a)

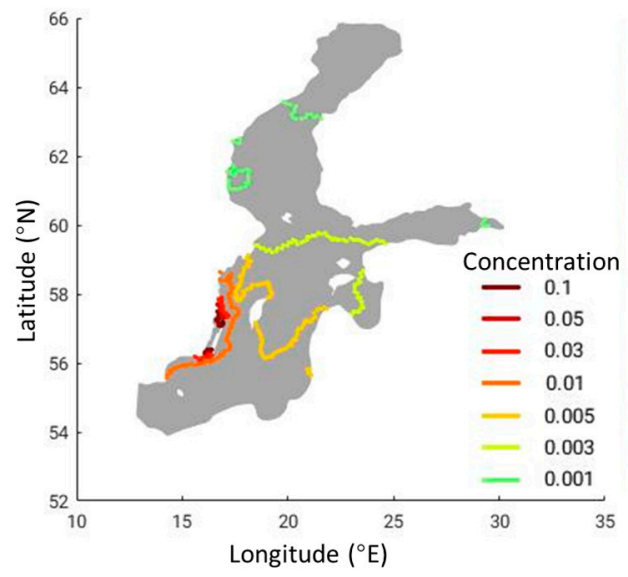

(b)

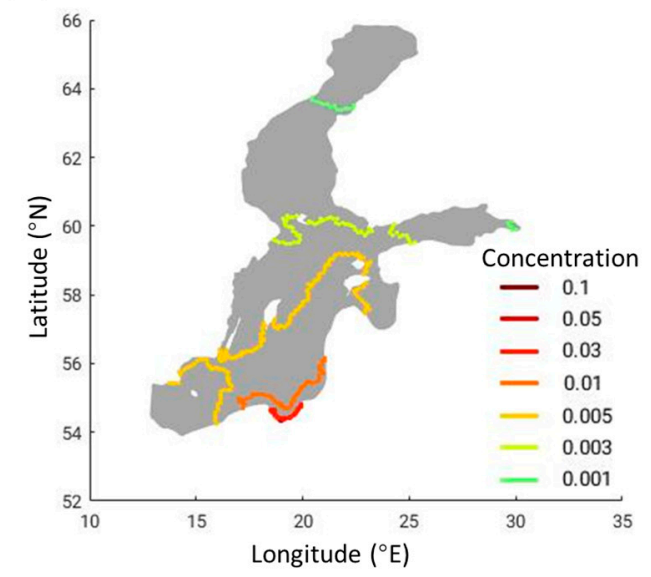

Figure 7. Isolines of maximum solute concentration over the simulation period in the equivalent release scenario. (a) Kalmar County coast case; (b) Vistula River coast case.

In the total nutrient scenario, the solute spreading from the Kalmar County releases is shown as a baseline result (Figure 8a) for comparison with the solute spreading from the 35.6 times and 55.1 times higher total releases from the Vistula catchment (Figure 8b,c) in proportion to its higher TN and TP loads, respectively. As expected, the total solute spreading into the Baltic Sea is much wider and stronger for the much higher total Vistula River releases than the total Kalmar County releases. While relatively high solute concentration levels resulting from the Kalmar County releases are mostly contained in the coastal source vicinity, the spreading of such concentration levels resulting from the Vistula River catchment reaches far from the Gulf of Gdansk to the north of the Baltic Sea. In contrast, for the per-capita nutrient scenario, the relatively high concentration contributions from the on-average 4.3 and 2.7 times higher TN- and TP-proportional solute releases from each person in Kalmar County spread much further into the Baltic Sea than the corresponding concentration contributions from the smaller average releases of each person in the Vistula River catchment (Figure 9). Particularly for TP, relatively high solute concentration levels resulting from the Vistula River per-capita releases are mostly contained in the coastal source vicinity.
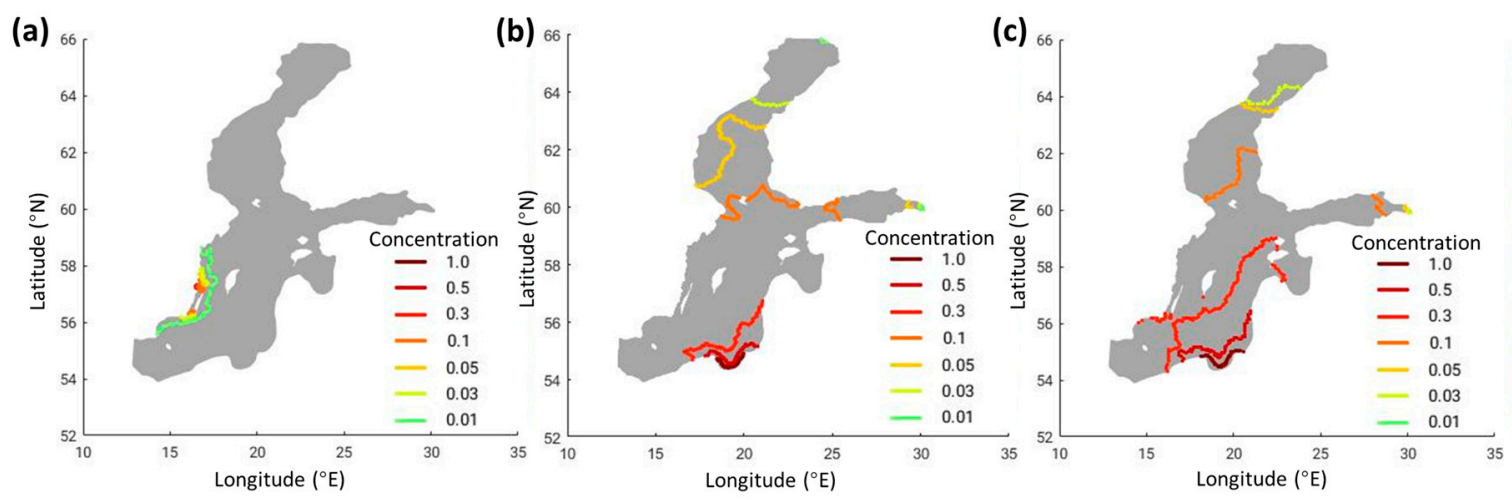

Figure 8. Isolines of maximum solute concentration over the simulation period for the total nutrient release scenario. (a) Kalmar County coast case with standard solute release; (b) Vistula River coast case with total nitrogen (TN)-proportional 35.6 times higher solute release; (c) Vistula River coast case with total phosphorus (TP)-proportional 55.1 times higher solute release. 
(a)

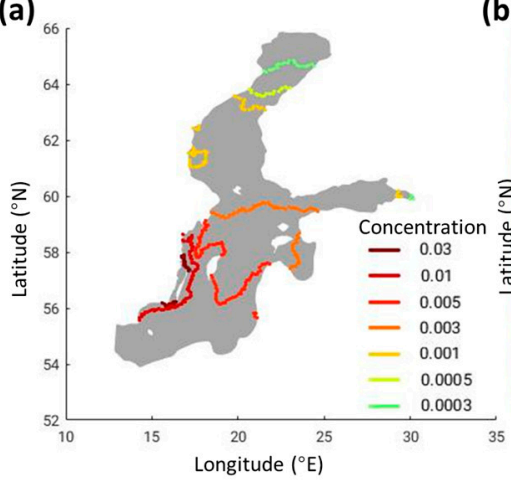

(b)

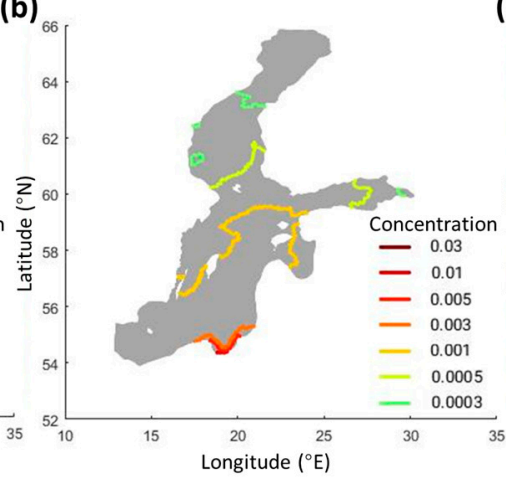

(c)

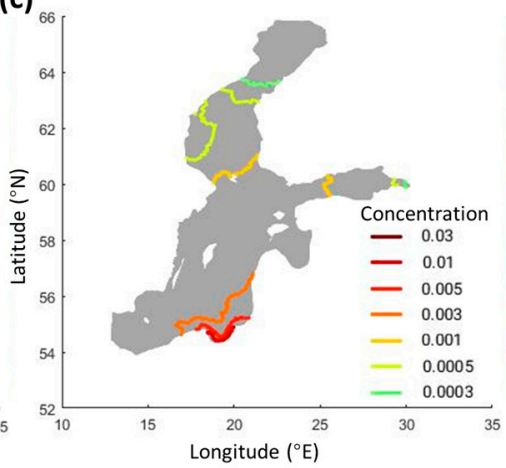

Figure 9. Isolines of maximum solute concentration over the simulation period for the per-capita nutrient release scenario. (a) Kalmar County coast case with standard solute release; (b) Vistula River coast case with TN-proportional 4.3 times lower solute release; (c) Vistula River coast case with TP-proportional 2.7 times lower solute release.

The much greater population in the Vistula River catchment, thus, in total contributes to relatively high nutrient concentration levels extending much further into the Baltic Sea, compared to the total concentration contributions of the much smaller population in the coastal Kalmar County catchment. However, if one considers the Baltic Sea concentration impact of the average person in each catchment, this is on average considerably greater from an individual in Kalmar County than in the Vistula River catchment. This may be compared with the international agreement on nutrient load reductions required from each Baltic country, the Baltic Sea Action Plan (BSAP) [44]. This requires average per-capita load reductions by around $2.1 \mathrm{~kg} /$ year for TN and $0.03 \mathrm{~kg} /$ year for TP from the average Swedish inhabitant, and around $1.6 \mathrm{~kg} /$ year for TN and $0.23 \mathrm{~kg} /$ year for TP from the average Polish inhabitant. Compliance with such per-capita reduction requirements would allow remaining load contributions of around $19.5 \mathrm{~kg} /$ year for TN and $0.62 \mathrm{~kg} /$ year for TP from the average Kalmar County inhabitant, but only $3.4 \mathrm{~kg} /$ year for TN and $0.005 \mathrm{~kg} /$ year for TP from the average Vistula catchment inhabitant. These comparisons highlight an important fairness issue for the distribution of nutrient mitigation efforts and costs among the people and taxpayers of different countries around the Baltic Sea.

\subsection{Relevance of the Numerical Experimentation Results}

To our best knowledge, no systematic release-transport field experiment with controlled tracer releases, comparable to the numerical experiments of this study, has so far been conducted in any of the two Baltic coastal study cases. The results of this study are, thus, not directly comparable with any existing field experimentation data. Nevertheless, the hydrodynamic model used for the current controlled transport experimentation has been tested and validated against relevant field data in previous work [13], with the validated hydrodynamics, in turn, determining the physical solute transport simulated in this study. The parallel investigation has also shown that such hydrodynamic modelling coupled with a relevant biogeochemical model can sufficiently well reproduce specific nutrient, and other eutrophication conditions, in the Baltic Sea and its coasts [11].

Directly comparable field experimentation would require controlled release of solute from the coastal location, with the solute tagged to act as a tracer for the subsequent physical transport from a conclusively known source. Moreover, the spreading pattern would need to be systematically monitored along the transport pathways of the solute/tracer into the Baltic Sea. This is not an easy field experiment to do, and data for solutes already in the sea are also not directly useful for transport simulation testing since their release, and physical transport conditions are compounded with and obscured by numerous other drivers and biogeochemical processes in the sea. These field experimentation and data interpretation difficulties are also a main reason why controlled numerical experimentation is needed to advance our understanding of physical transport under different coastal conditions and solute release scenarios, 
which cannot be readily studied in the field. Such numerical experimentation results, and the new knowledge gained from them and new hypotheses that can be formulated based on that knowledge can also be used for guidance of future attempts to efficiently conduct such difficult field experiments.

The simulation results for the equivalent release scenario show that, if the solute is released into each of the two study coasts at equal input loads (of whichever absolute value), then the physical transport into the Baltic Sea yields more or less similar sea concentrations for both coastal cases. This implies that the physical transport from coast to sea does not yield major differences in concentration spreading within the sea, even though the coastal locations, and their flows and local concentration values are different. This sea concentration similarity for equal coastal input loads (despite other coastal differences) further implies that any major concentration differences seen in the sea for solute released from the two coastal cases should predominantly depend on differences in input loads from the land between the coasts. This is indeed also what emerges from the simulations of the two release scenarios with different coastal input loads selected in proportion to the total or per-capita TN and TP input loads for the two coasts. The physical transport, thus, transfers input load differences at the coasts to proportional concentration differences in the sea.

The main implication of these results is that differences between the coasts in land-released input loads of, e.g., TN (or TP, or another pollutant) may also yield proportional concentration differences in the sea, if associated biogeochemical processes act more or less similarly along the physical transport pathways from coast to sea. At any rate, even if biogeochemistry destroys the transport-maintained proportionality in sea concentrations, the differences between total and per-capita TN and TP input loads still remain as an essential fairness issue between the two coastal cases, considering that the BSAP nutrient reduction requirements apply to the input loads at the coasts and not to sea concentrations.

Furthermore, the nutrient-related solute release scenarios in this study remain relevant even though the nutrient data used to quantify them are for earlier periods (1984-2000 for the Kalmar case and 1980-1993 for the Vistula case). Since then, nutrient concentrations discharged from Kalmar County have remained stable, or even increased rather than decreased, over the period 2003-2013 (see [45] and specifically the trend data for TP and TN at the Kalmar coast in their figures 7 and 8, respectively). Meanwhile reported flow-normalized nutrient loads at the Vistula coast have been stable for TP (statistically insignificant decrease) and decreasing (statistically significant) for TN over the period 1995-2014 (see [24] and specifically the TP and TN trends in their figures 29 and 28, respectively). These trends support (and even strengthen) our conclusion of an important per-capita fairness issue, as the nutrient differences between the coastal cases have remained more or less similar (or even widened with the slight Kalmar increases and slight, or for TN even significant, Vistula decreases) compared to the earlier data used to define the nutrient-related release scenarios.

\section{Conclusions}

The equivalent release scenario of our controlled numerical experimentation, which compares simulated solute spreading from equal input loads in two coastal cases with different hydro-climatic, geomorphological and hydrodynamic conditions, highlights the importance of these coastal conditions within identified influence zones. The solute spreading patterns in these coastal zones depend greatly on the coastal flows and their interactions with the linked main marine currents. The marine spreading patterns through the whole Baltic Sea, however, are similar for the two coastal cases, with similarly high solute concentration levels spreading to more or less similar locations into the sea, despite large differences in the local flow situations at the coasts.

The main drivers of local coastal flow and transport conditions are site-specific, and thus, differ between the two coastal study cases. In the Kalmar case, (negative) northwards wind conditions drive (negative) northwards and also eastwards flow conditions that in turn determine the local spreading pattern of the coastal solute concentrations. In the Vistula case, where flow interacts with and is predominantly influenced by stable marine currents, the driving effects of the local wind is weaker. Solute spreading in the bay parts with the predominant coastal flow is influenced by this flow 
(circulating eastwards and northwards). Solute spreading in the bay parts that interact more with the stable marine current by the bay exhibits no or small correlation with the local coastal wind and water flow conditions.

For the nutrient-proportional solute release and spreading scenarios, the total solute loading from the large and highly-populated Vistula River catchment is much greater and, as such, has much greater reach and concentration impacts in the Baltic Sea than the total loading from the Kalmar County catchment, which is smaller and has much lower population. The per-capita nutrient load and Baltic Sea concentration contributions of the average Vistula catchment inhabitant, however, are considerably smaller and have smaller reach and impacts in the sea than those of the average Kalmar County inhabitant.

For comparison, if each person in the whole Baltic Sea catchment was on average allowed similarly low nutrient contributions to the sea as the average person in the Vistula catchment, the per-capita nutrient contributions of the Kalmar County would have to be reduced by around $16.5 \mathrm{~kg} / \mathrm{year}$ for $\mathrm{TN}$ and $0.39 \mathrm{~kg} /$ year for TP. These would be much greater reductions than the BSAP [44] requires per-capita from Sweden $(2.1 \mathrm{~kg} /$ year for TN, $0.03 \mathrm{~kg} /$ year for TP; with even these, agreed reductions still largely remaining to be met [45]). Conversely, if each person in the Baltic Sea catchment was on average allowed similarly high nutrient contributions to the sea as the average Kalmar County inhabitant, the per-capita nutrient contributions of the Vistula catchment could increase by around $16.5 \mathrm{~kg} /$ year for TN and $0.39 \mathrm{~kg} /$ year for TP_instead of the per-capita reductions that the BSAP requires per-capita from Poland (1.64 kg/year for TN, $0.23 \mathrm{~kg} /$ year for TP). Such comparisons highlight a degree of unfairness in the per-capita distributions of nutrient contribution allowance and/or eutrophication mitigation burden around the Baltic. This may hamper and should be considered in further mitigation efforts and supporting research.

Supplementary Materials: The following are available online at http://www.mdpi.com/2073-4441/11/7/1407/s1, Power Spectral Density: Implementation description, Figure S1: Power Spectral Density analysis for the Kalmar County coast case using average value for water velocity and solute concentration, Figure S2: Magnitude-squared coherence of solute concentration with different forcing variables for the Kalmar County coast case using average value for water velocity and solute concentration, Figure S3: Power spectral density analysis of relatively strongly correlated variables for the Vistula River coast case using point values for water velocity and solute concentration, Figure S4: Magnitude-squared coherence of solute concentration with different forcing variables for the Vistula River coast case using point values for water velocity and solute concentration, Figure S5: Power spectral density analysis for the Vistula River coast case using point values for water velocity and solute concentration for comparison with Figure S3, Figure S6: Magnitude-squared coherence of solute concentration with different forcing variables for the Vistula River coast case using point values for water velocity and solute concentration.

Author Contributions: Conceptualization, G.D., V.C. and Y.C.; methodology, G.D. and V.C.; model setup, Y.C. and V.C.; simulation, Y.C.; validation, Y.C. and V.C.; formal analysis, Y.C., G.D. and V.C.; writing-original draft preparation, Y.C.; writing-review and editing, G.D., Y.C. and V.C.; visualization, Y.C.; supervision, V.C. and G.D.

Funding: This research was funded by the European Commission (project COASTAL, 773782), and the China Scholarship Council (CSC).

Conflicts of Interest: The authors declare no conflict of interest.

\section{References}

1. Hannerz, F.; Destouni, G. Spatial characterization of the Baltic Sea drainage basin and its unmonitored catchments. AMBIO 2006, 35, 214-220. [CrossRef] [PubMed]

2. Conley, D.J.; Björck, S.; Bonsdorff, E.; Carstensen, J.; Destouni, G.; Gustafsson, B.G.; Hietanen, S.; Kortekaas, M.; Kuosa, H.; Markus Meier, H.E.; et al. Hypoxia-related processes in the Baltic Sea. Environ. Sci. Technol. 2009, 43, 3412-3420. [CrossRef] [PubMed]

3. Pastuszak, M.; Witek, Z.; Nagel, K.; Wielgat, M.; Grelowski, A. Role of the Oder estuary (Southern Baltic) in transformation of the riverine nutrient loads. J. Mar. Syst. 2005, 57, 30-54. [CrossRef]

4. Radtke, H.; Neumann, T.; Voss, M.; Fennel, W. Modeling pathways of riverine nitrogen and phosphorus in the Baltic Sea. J. Geophys. Res. Ocean. 2012, 117. [CrossRef] 
5. Corell, H.; Döös, K. Difference in particle transport between two coastal areas in the Baltic Sea investigated with high-resolution trajectory modeling. AMBIO 2013, 42, 455-463. [CrossRef] [PubMed]

6. Engqvist, A.; Döös, K.; Andrejev, O. Modeling water exchange and contaminant transport through a Baltic coastal region. AMBIO 2006, 35, 435-447. [CrossRef]

7. Döös, K.; Engqvist, A. Assessment of water exchange between a discharge region and the open sea-A comparison of different methodological concepts. Estuar. Coast. Shelf Sci. 2007, 74, 709-721. [CrossRef]

8. Delpeche-Ellmann, N.C.; Soomere, T. Investigating the Marine Protected Areas most at risk of current-driven pollution in the Gulf of Finland, the Baltic Sea, using a Lagrangian transport model. Mar. Pollut. Bull. 2013, 67, 121-129. [CrossRef]

9. Myrberg, K.; Andrejev, O. Modelling of the circulation, water exchange and water age properties of the Gulf of Bothnia. Oceanologia 2006, 48, 55-74.

10. Jönsson, B.; Lundberg, P.A.; Döös, K. Baltic sub-basin turnover times examined using the Rossby Centre Ocean Model. AMBIO 2004, 33, 257-260. [CrossRef]

11. Vigouroux, G.; Destouni, G.; Jönsson, A.; Cvetkovic, V. A scalable dynamic characterisation approach for water quality management in semi-enclosed seas and archipelagos. Mar. Pollut. Bull. 2019, 139, 311-327. [CrossRef] [PubMed]

12. Gren, I.M.; Destouni, G. Does Divergence of Nutrient Load Measurements Matter for Successful Mitigation of Marine Eutrophication? AMBIO 2012, 41, 151-160. [CrossRef] [PubMed]

13. Chen, Y.; Vigouroux, G.; Bring, A.; Cvetkovic, V.; Destouni, G. Dominant Hydro-Climatic Drivers of Water Temperature, Salinity, and Flow Variability for the Large-Scale System of the Baltic Coastal Wetlands. Water 2019, 11, 552. [CrossRef]

14. Jarsjö, J.; Shibuo, Y.; Destouni, G. Spatial distribution of unmonitored inland water discharges to the sea. J. Hydrol. 2008, 348, 59-72. [CrossRef]

15. Destouni, G.; Shibuo, Y.; Jarsjö, J. Freshwater flows to the sea: Spatial variability, statistics and scale dependence along coastlines. Geophys. Res. Lett. 2008, 35, L18401. [CrossRef]

16. Quin, A.; Destouni, G. Large-scale comparison of flow-variability dampening by lakes and wetlands in the landscape. Land Degrad. Dev. 2018, 29, 3617-3627. [CrossRef]

17. Kubiak-Wójcicka, K.; Bąk, B. Monitoring of meteorological and hydrological droughts in the Vistula basin (Poland). Environ. Monit. Assess. 2018, 190, 691. [CrossRef] [PubMed]

18. Placke, M.; Meier, M.; Gräwe, U.; Neumann, T.; Frauen, C.; Liu, Y. Long-term mean circulation of the Baltic Sea as represented by various ocean circulation models. Front. Mar. Sci. 2018, 5. [CrossRef]

19. Dargahi, B.; Cvetkovic, V. Hydrodynamics and Transport Characterization of the Baltic Sea 2000-2009 Report. The Royal Institute of Technology, 2014. Available online: https://balsysproject.files.wordpress. com/2015/08/hydrodynamic-and-transport-characterization-of-the-baltic-sea-2000-2009.pdf (accessed on 20 November 2018).

20. Meier, H.M. Modeling the pathways and ages of inflowing salt-and freshwater in the Baltic Sea. Estuar. Coast. Shelf Sci. 2007, 74, 610-627. [CrossRef]

21. Destouni, G.; Hannerz, F.; Prieto, C.; Jarsjö, J.; Shibuo, Y. Small unmonitored near-coastal catchment areas yielding large mass loading to the sea. Glob. Biogeochem. Cycles 2008, 22, GB4003. [CrossRef]

22. Levi, L.; Cvetkovic, V.; Destouni, G. Data-driven analysis of nutrient inputs and transfers through nested catchments. Sci. Total Environ. 2018, 610, 482-494. [CrossRef] [PubMed]

23. Helsinki Commission (HELCOM). The Fifth Baltic Sea Pollution Load Compilation (PL-5) Baltic Sea Environment Proceedings No. 128; Helsinki Commission: Helsinki, Finland, 2011.

24. Helsinki Commission (HELCOM). Input of Nutrients by the Seven Biggest Rivers in the Baltic Sea Region, Baltic Sea Environment Proceedings No. 163; Helsinki Commission: Helsinki, Finland, 2018.

25. Chen, C.; Liu, H.; Beardsley, R.C. An unstructured grid, finite-volume, three-dimensional, primitive equations ocean model: Application to coastal ocean and estuaries. J. Atmos. Ocean. Technol. 2003, 20, 159-186. [CrossRef]

26. Mellor, G.L.; Yamada, T. Development of a turbulence closure model for geophysical fluid problems. Rev. Geophys. 1982, 20, 851-875. [CrossRef]

27. Chen, C.; Huang, H.; Beardsley, R.C.; Xu, Q.; Limeburner, R.; Cowles, G.W.; Sun, Y.; Qi, J.; Lin, H. Tidal dynamics in the Gulf of Maine and New England Shelf: An application of FVCOM. J. Geophys. Res. Ocean. 2011, 116. [CrossRef] 
28. Beardsley, R.C.; Chen, C.; Xu, Q. Coastal flooding in Scituate (MA): A FVCOM study of the 27 December 2010 nor'easter. J. Geophys. Res. Ocean. 2013, 118, 6030-6045. [CrossRef]

29. Wei, J.; Malanotte-Rizzoli, P.; Eltahir, E.A.; Xue, P.; Xu, D. Coupling of a regional atmospheric model (RegCM3) and a regional oceanic model (FVCOM) over the maritime continent. Clim. Dyn. 2014, 43, 1575-1594. [CrossRef]

30. European Centre for Medium-Range Weather Forecasts (ECMWF). Available online: https://www.ecmwf.int/ en/forecasts/datasets/archive-datasets/reanalysis-datasets/era-20c (accessed on 6 September 2016).

31. Objectively Analyzed Air-Sea Fluxes for the Global Oceans Project, Woods Hole Oceanographic Institution (WHOI). Available online: //oaflux.whoi.edu/index.html (accessed on 29 January 2016).

32. International Satellite Cloud Climatology Project (ISCCP). Available online: https://isccp.giss.nasa.gov/ projects/flux.html (accessed on 29 January 2016).

33. Swedish Meteorological and Hydrological Institute (SMHI), Oceanografiska Observationer. Available online: https://opendata-download-ocobs.smhi.se/explore/ (accessed on 29 June 2016).

34. Swedish Meteorological and Hydrological Institute (SMHI), Marina Miljöövervakningsdata. Available online: http://www.smhi.se/klimatdata/oceanografi/havsmiljodata/2.2596 (accessed on 23 November 2016).

35. Swedish Meteorological and Hydrological Institute (SMHI), Vattenwebb. Available online: https: //vattenwebb.smhi.se/station/\# (accessed on 25 February 2012).

36. The Global Runoff Data Centre, 56068 Koblenz, Germany (GRDC). Available online: http://www.bafg.de/ GRDC/EN/02_srvcs/21_tmsrs/211_ctlgs/catalogues_node.html (accessed on 15 March 2015).

37. Thompson, R.O. Coherence Significance Levels. J. Atmos. Sci. 1979, 36, 2020-2021. [CrossRef]

38. Miles, J.H. Estimation of signal coherence threshold and concealed spectral lines applied to detection of turbofan engine combustion noise. J. Acoust. Soc. Am. 2011, 129, 3068-3081. [CrossRef]

39. Kustvattenkommitten. Miljorapport för 2001 från Kustvattenkommitten i Kalmar Län. 2001. Available online: http://www.kalmarlanskustvatten.org/data/arsrapporter/kalmar01.pdf (accessed on 17 March 2019).

40. Länsstyrelsen i Kalmar län. Orsaker till Övergödning av Östersjöns Kustvatten: Källfördelning för Närsaltutsläpp i Kalmar Län. 2000. Available online: http://urn.kb.se/resolve?urn=urn:nbn:se:naturvardsverket: diva-4565 (accessed on 17 March 2019).

41. Stålnacke, P.; Grimvall, A.; Sundblad, K.; Tonderski, A. Estimation of riverine loads of nitrogen and phosphorus to the Baltic Sea, 1970-1993. Environ. Monit. Assess. 1999, 58, 173-200. [CrossRef]

42. Statistiska Centralbyrån (SCB), Folkmängd i Riket, Län och Kommuner 30 September 2017 och Befolkningsförändringar 1 July-30 September 2017. Available online: https://www.scb.se/hitta-statistik/ statistik-efter-amne/befolkning/befolkningens-sammansattning/befolkningsstatistik/pong/tabell-ochdiagram/kvartals--och-halvarsstatistik--kommun-lan-och-riket/kvartal-3-2017/ (accessed on 17 March 2019).

43. Nilsson, S. International River Basins in the Baltic Sea Region. Report: BSR INTERREG III B Programme Project Report. 2006. Available online: https://www.baltex-research.eu/material/downloads/riverbasins.pdf (accessed on 17 March 2019).

44. Helsinki Commission (HELCOM). HELCOM Baltic Sea Action Plan (Adopted by the HELCOM Ministerial Meeting, Krakow, Poland 15th November 2007); Helsinki Commission: Helsinki, Finland, 2007.

45. Destouni, G.; Fischer, I.; Prieto, C. Water quality and ecosystem management: Data-driven reality check of effects in streams and lakes. Water Resour. Res. 2017, 53, 6395-6404. [CrossRef]

(C) 2019 by the authors. Licensee MDPI, Basel, Switzerland. This article is an open access article distributed under the terms and conditions of the Creative Commons Attribution (CC BY) license (http://creativecommons.org/licenses/by/4.0/). 